\title{
An alternative to grapheme-phoneme conversion rules?
}

\author{
MARCUS TAFT \\ University of New South Wales, Kensington, New South Wales 2033, Australia
}

\begin{abstract}
When orthographic factors were tightly controlled in a lexical decision task, it was observed that orthographic similarity rather than homophony with a word led to increased reaction times to nonwords. This result suggested that the peeudohomophone effect is not a phonological effect. Instead, a conversion of the graphemes of a stimulus item into different graphemes via a set of grapheme-grapheme conversion rules was supported. When phonological factors were tightly controlled and orthographic similarity varied, evidence for the existence of grapheme-grapheme rules was provided in both a lexical decision task and a task in which subjects were required to say whether an item was pronounced in the same way as a word. Even in the latter task, in which the likelihood of phonological recoding was optimized, it appeared that grapheme-phoneme rules were rarely, if ever, used.
\end{abstract}

The finding that nonwords are classified in a lexical decision task more slowly when they are pronounced in the same way as a real word (e.g., BRANE) than when they are not (e.g., BRATE), has been taken as evidence that nonwords are converted into a phonological representation via grapheme-phoneme rule conversion when they are processed (Coltheart, Davelaar, Jonasson, \& Besner, 1977; Gough \& Cosky, 1977; Patterson \& Marcel, 1977; Rubenstein, Lewis, \& Rubenstein, 1971). This has been called the pseudohomophone effect. On the other hand, the failure to consistently find such a homophone effect for word items has been taken as evidence that words are normally processed on the basis of their orthography rather than their phonology (Coltheart, 1978; Coltheart et al., 1977). Taken together, the presence of a pseudohomophone effect and the general lack of a homophone effect for words implies that there are two access routes to the lexicon, one visual and one phonological, and that both are used when processing printed material. However, the phonological route is slower than the visual one and exerts an influence on response times only when the visual route fails to find a lexical entry, that is, when the item presented is a nonword.

Following from this, the pseudohomophone effect has been used as a diagnostic to test the extent to which a reader uses phonological rules. For example, Patterson and Marcel (1977) report two dyslexic patients whose failure to produce a pseudohomophone effect (along with their inability to read nonwords) was taken to mean that these patients had a deficit in their ability to convert the printed word into its phonological form by rule.

Related to the pseudohomophone effect is a task that requires subjects to explicitly report whether a nonword is pronounced in the same way as a proper word (e.g., BRANE) or not (e.g., BRATE). Again, the ability to perform this task has been used as a diagnostic of a reader's ability to use grapheme-phoneme rules. For example, Saffran and Marin (1977) examined the pattern of errors made on this task by a dyslexic patient and concluded that the patient was unable to use phonological conversion rules. Ability to perform this task was also used by Baron and Strawson (1976) to determine whether a group of normal readers was phonologically oriented or visually oriented.

The assumption that is made in explaining both the pseudohomophone effect and the ability to say whether or not a nonword is pronounced like a word is that a phonological representation of the nonword is generated by a set of grapheme-phoneme conversion rules and that this is then matched with a phonologically represented lexical entry. In order to be certain that this assumption is correct, however, it must be shown that pseudohomophones do not show their effects simply because they are orthographically more similar to real words than are nonhomophonic nonwords. For this reason, Coltheart et al. (1977) attempted to match their pseudohomophones and their nonhomophonic nonwords on orthographic similarity to English. They did this by changing only one letter of each pseudohomophone to form a nonhomophone. For example, the pseudohomophone ILE was matched with the nonhomophone IFE, and FRAZE was matched with FRUZE. Coltheart et al. supposed that the changing of only one letter meant that the nonhomophones were just as orthographically similar to real words as were the pseudohomophones. But that is not really true. For example, ILE is orthographically more similar to a word (ISLE) than IFE is and FRAZE is orthographically more similar to a word (PHRASE) than FRUZE is. To be sure that orthographic similarity is not confounded with homophony, then, one must use pseudohomophones and nonhomophones that are matched exactly on their similarity to real words. This can be achieved in the following way. 
There are orthographic structures in English that can be pronounced in more than one way (e.g., OST in GHOST and FROST). If one constructs a pseudohomophone by changing such an orthographic structure appropriately (e.g., GHOAST), then one can also construct a nonhomophone by making exactly the same change (e.g., FROAST). In this way, the nonhomophonic nonword is related orthographically to a real word in exactly the same way as the pseudohomophone is. Therefore, if the pseudohomophone findings results from phonological recoding rather than orthographic similarity, then pseudohomophones like GHOAST should take longer to classify as nonwords than should nonhomophones like FROAST. If, on the other hand, the effect is an orthographic one, then GHOAST and FROAST should take equally longer to classify as nonwords than a nonword like PLOAST, which is not orthographically related to a real word. Experiment 1 was carried out to test these predictions.

\section{EXPERIMENT 1}

\footnotetext{
Method

Materials. Three types of nonword were constructed : pseudohomophones (H-nonword condition), nonhomophones that were orthographically similar to a word ( $O$-nonword condition), and nonhomophones that were not orthographically similar to a word ( $\mathrm{N}$-nonword condition). There were 20 nonwords in each condition, matched in triplets on their orthographic structure. In addition, the words from which the H-condition nonwords and the O-condition nonwords were derived were matched over all items on log frequency according to Carroll, Davies, and Richman (1971). Examples of item triplets were: GHOAST (from GHOST), FROAST (from FROST), PLOAST; PLEED (from PLEAD), DREED (from DREAD), CLEED; and JERM (from GERM), JIFT (from GIFT), JILK. All of the nonword items are presented in the appendix.

The word items used in the experiment were also set up in order to look at the effects of orthographic similarity to other words. Fifteen H-condition words (i.e., homophonic words, like PANE) were compared to 15 nonhomophonic control words matched on frequency and length (e.g., JERK), and 15 O-condition words (i.e., nonhomophonic words that were orthographically similar to another word; like GREET, which is similar to GREAT) were compared to 15 matched control words (e.g., CREST). The H-condition words could not be compared directly to the $\mathrm{O}$-condition words because of the difficulty of finding appropriately matched items. The graphemic ending of each $\mathrm{H}$-condition word was always a less frequently occurring ending than that of the word with which it was homophonic. For example, -ANE is a less common ending than is -AIN. In addition, each H-condition word was always less frequent than the word with which it was homophonic (e.g., PANE is less frequent than PAIN). The same principles were followed with the O-condition words. For example, -EET is a less frequent ending than is -EAT and GREET is a less frequent word than is GREAT.

Procedure. Subjects were presented the stimulus items in one of four different random orders. Stimuli were presented on a video display unit under computer control, with each item being presented for $800 \mathrm{msec}$. The interstimulus interval was 4 sec. Subjects were instructed to press a right-hand "yes" button if the item presented was a word and to press a lefthand "no" button if the item presented was not a word. They were also told to respond as quickly, but as accurately, as they could.
}

Thirty subjects were used in the experiment, each being given course accreditation for their participation.

\section{Results}

Table 1 provides the mean reaction times for the nonword and word items of the first experiment.

An analysis of the reaction times to the nonwords revealed that, while the $\mathrm{H}$ nonwords differed from the $\mathrm{N}$ nonwords [ $\mathrm{min} \mathrm{F}^{\prime}(1,50)=8.67, \mathrm{p}<.01$ ] (the normal pseudohomophone effect), there was no difference at all between the $\mathrm{H}$ nonwords and the $\mathrm{O}$ nonwords (both $F_{1}$ and $F_{2}<1$ ). An analysis of the errors showed the same pattern $\left[H\right.$ vs. $N$ nonwords, $\min F^{\prime}(1,49)=4.17$, $\mathrm{p}<.05 ; \mathrm{H}$ vs. $\mathrm{O}$ nonwords, $\left.\min \mathrm{F}^{\prime}<1\right]$. The $\mathrm{O}$ nonwords differed from the $\mathrm{N}$ nonwords also, but only on reaction time $\left[\min F^{\prime}(1,34)=7.08, p<.02\right]$. The error difference between $\mathrm{O}$ nonwords and $\mathrm{N}$ nonwords was significant only on the subject analysis $\left[F_{1}(1,29)=\right.$ $\left.5.37, \mathrm{p}<.05 ; \mathrm{F}_{2}(1,19)=4.02, \mathrm{p}>.05\right]$.

The word items were analyzed using a 2 by 2 analysis of variance, the main effects being $\mathrm{H}$ and $\mathrm{O}$ words vs. the control conditions (orthographic similarity), and $\mathrm{H}$ conditions (experimental and control) vs. $O$ conditions (experimental and control). The main effect of orthographic similarity for reaction times was significant only on the subjects analysis $\left[F_{1}(1,29)=8.394, p<.02\right.$; $\left.\mathrm{F}_{2}(1,29)=1.63, \mathrm{p}>.05\right]$, as was the difference between the $H$ conditions and the $O$ conditions $\left[F_{1}(1,29)=\right.$ $\left.8.287, p<.02 ; F_{2}(1,56)=2.115, p>.05\right]$. The interaction between these two effects was not significant $\left(\min \mathrm{F}^{\prime}<1\right)$. Analysis of the errors revealed no significant differences.

\section{Discussion}

It is apparent from the data that the pseudohomophone effect may not be a phonological effect at all. Pseudohomophones did not differ in the experiment from those nonwords that were not homophonic with but were orthographically similar to words. Therefore, it appears that the orthographic similarity of pseudohomophones to real words is sufficient to produce a delay in classification times relative to nonwords that are not similar to real words.

Table 1

Mean Reaction Times (in Milliseconds) and Standard Errors Along with Percentage Error Rate (PE) for the Nonword and Word Items of Experiment 1

\begin{tabular}{llllr}
\hline \multicolumn{1}{c}{ Condition } & Example & RT & SE & PE \\
\hline & Nonwords & & & \\
H Nonwords & GHOAST & 750 & 26 & 9 \\
O Nonwords & FROAST & 752 & 29 & 7 \\
N Nonwords & PLOAST & 715 & 25 & 3 \\
& Words & & & \\
H Words & PANE & 664 & 26 & 12 \\
H Control Words & JERK & 657 & 21 & 11 \\
O Words & GREET & 650 & 24 & 8 \\
O Control Words & CREST & 617 & 20 & 4 \\
\hline
\end{tabular}


Such a conclusion has major implications for theories of word recognition that cite the pseudohomophone effect as evidence for the use of grapheme-phoneme conversion rules. According to the present results, the pseudohomophone effect should be seen instead as the result of confusions resulting from visual access (that is, access that is not mediated by a phonological code).

Similarly, when a dyslexic patient fails to produce a pseudohomophone effect (Patterson \& Marcel, 1977), the results presented here would imply that the patient is simply not being influenced by orthographic similarity. This, however, seems to be untrue. On the contrary, Saffran and Marin (1977) have demonstrated that such dyslexic patients are very much influenced by orthographic similarity when required to make a response about the pronunciation of an item. For example, a patient might say that MANOR is homophonic with MINOR, rather than with MANNER, or that RAYNE is pronounced as RAYON, rather than RAIN. How can this fact be reconcilable with the present results?

It is possible that there are in fact two types of orthographic similarity: gross graphemic similarity and rule-governed similarity. The former is a matter of the similarity of the overall graphemic pattern of the presented item with the word that is accessed (e.g., RAYNE and RAYON are orthographically similar in this way). The latter refers to the interchanging of particular graphemes with other graphemes that can be pronounced identically and that do not violate laws of orthographic cooccurrence (called orthotactic rules by Taft, 1979a). For example, EA and EE are interchangeable in this way, but EA and OA are not. Hence, NEAT and NEET are orthographically similar in this sense, but NEAT and NOAT are not. Similarly, DREAD and DREED are orthographically similar, even though they are not homophonic with each other. $G$ and $J$ can be interchangeable also, but not in every environment. For example, they can be interchanged in GIMP, but not in GRIMP or LING, since JR and NJ are orthotactic violations. Possibly, then, normal subjects are influenced by the rule-governed type of orthographic similarity when performing the lexical decision task, whereas dyslexic subjects are unable to apply these graphemegrapheme conversion rules and are influenced solely by gross graphemic similarity.

McQuade (1981) has reported that the size of the pseudohomophone effect is variable, depending upon the strategies adopted by the subjects. This implies that the pseudohomophone effect must be explained in terms of some procedure over which subjects have some control (either conscious or unconscious). Delay in reaction time through gross graphemic confusions between nonwords and words is unlikely to be under strategic control. Application of rules, on the other hand, could easily be open to strategic control: But rather than grapheme-phoneme rules, as McQuade proposes, these rules could be grapheme-grapheme rules. Similarly Davelaar, Coltheart, Besner, and
Jonasson (1978) have found that the homophone effect is also open to strategic control, thus implying the use of rules. Davelaar et al. obtained a homophone for words when pseudohomophones were not included in the experiment, but no effect when they were. Possibly, then, the lack of any effects significant by $\min F^{\prime}$ for the word items in the present experiment was a result of there being nonwords in the experiment that were orthographically similar to real words. If there had been no such nonwords, then significant effects on the word items might have been observed.

If the pseudohomophone effect and the homophone effect are under strategic control and if the explanation for these effects is in terms of orthographic similarity (as suggested by Experiment 1), then that implies that the orthographic similarity involved is rule governed. The purpose of the second experiment, therefore, is to look more directly at the question of the existence of rule-governed orthographic similarity, that is, the existence of grapheme-grapheme conversion rules.

\section{EXPERIMENT 2}

In Experiment 1, it was found that nonwords that were orthographically similar to words took longer to classify than those that were not. It is unclear from this experiment, however, what type of orthographic similarity was involved. The $O$ nonwords were more similar to words than were the $\mathrm{N}$ nonwords, both on gross graphemic characteristics and on a rule-governed basis.

In order to separate these two types of orthographic similarity, two nonword conditions were designed so that they were matched on their general graphemic similarity to other words (and phonemic similarity) but varied in the nature of this similarity. For example, CHEECE is as graphemically (and phonemically) similar to CHEESE as BREECE is to BREEZE. Yet $\mathrm{C}$ and $\mathrm{S}$ are interchangeable in the sense that they both can be pronounced in the same way, whereas $\mathrm{C}$ and $\mathrm{Z}$ cannot. Hence, if lexical decision items are slowed by orthographic similarity of a gross graphemic type only, then CHEECE (O condition) should not differ from BREECE ( $G$ condition). If, on the other hand, they are slowed by the fact that the application of grapheme-grapheme rules leads to the erroneous accessing of a lexical entry, then O-condition nonwords should take longer to classify as nonwords than G-condition nonwords. Note also that if grapheme-phoneme rules are applied, rather than grapheme-grapheme rules, then the two conditions should not differ either, since / $x_{i}$ :s/ (the pronunciation of CHEECE) is as similar to $/ x_{i}: z /$ (the pronunciation of CHEESE) as /bri:s/ (the pronunciation of BREECE) is to /bri:z/ (the pronunciation of BREEZE).

\section{Method}

Materials. Twenty O-condition nonwords were matched with $20 \mathrm{G}$-condition nonwords on orthographic structure. An item was considered to be an $\mathrm{O}$-condition nonword if its pronunciation could be spelled differently to form a word. Examples of 
item pairs are CHEECE (from CHEESE) and BREECE (from BREEZE), BREEST (from BREAST) and CREEST (from CREST), and KELL (from CELL) and KEND (from SEND). Item pairs were designed so that, over all items, the nonwords in the two conditions differed by one letter from the same number of real words, through substitution or addition. Thus general graphemic similarity was controlled. Phonemic similarity was also controlled in that the relationship between the pronunciation of an O-condition item and the word from which it was derived was the same as the relationship between the pronunciation of its G-condition pair and a real word. Thus the pronunciation of the O-condition item CHALC (namely, /čalk/) bears the same relationship to the pronunciation of CHALK (namely, $/ \check{c}$ כ:k/), as the G-condition HALC does to HAWK (namely, /halk/ and /ho:k/). In addition, while CHALC is graphemically only one letter different from CHALK, so HALC is only one letter different from HALT (as well as HALL, HALF, and TALC). All items are presented in the appendix.

There were also 40 words used as distractor items. These were of similar structure to the nonwords (e.g., SLEEVE, LEECH, MAIZE).

The procedure was identical to that of Experiment 1. There were 10 subjects.

\section{Results and Discussion}

The lexical decision results for the two nonword conditions are presented in Table 2.

The reaction time difference between the 0 -condition nonwords and the $\mathrm{G}$-condition nonwords proved to be significant $\left[\min \mathrm{F}^{\prime}(1,30)=4.37, \mathrm{p}<.05\right]$, but the error difference did not $\left(\min F^{\prime}<1\right)$.

This finding points to the existence of some sort of grapheme-grapheme rule system. The difference between the two nonword conditions could not result from general graphemic similarity, since the conditions were matched on this factor. Neither could the difference be attributed to phonological similarity, since this too was matched. The only difference between the 0 condition and the $G$ condition was that if each of the $O$ condition nonwords was respelled to produce the same pronunciation, they created a real word, whereas the G-condition nonwords respelled in this way did not create a real word. For example, CHEECE could be respelled as CHEESE while maintaining its pronunciation (as in GEESE); BREECE could similarly be respelled as BREESE, but this is not a word. BREEZE is derivable from BREECE, not by systematic respelling, but by simply exchanging one letter for another.

Subjects appear to have available to them a set of rules that tells them what letter combinations can be pronounced in the same way, and they appear to apply these rules when presented novel letter strings. This is not to say that gross graphemic similarity cannot also

Table 2

Mean Reaction Times (in Milliseconds) and Standard Errors Along With Percentage Error Rate (PE) for the Nonword Items of Experiment 2

\begin{tabular}{ccccc}
\hline Condition & Example & RT & SE & PE \\
\hline O Nonwords & CHEECE & 683 & 51 & 5 \\
G Nonwords & BREECE & 636 & 50 & 4 \\
\hline
\end{tabular}

influence decision times, but this factor was held constant in the present experiment. The results of Chambers (1979) provide evidence that approximate graphemic access does indeed take place in word recognition. Similarly, this experiment does not say whether phonological similarity influences decision times. However, the results of Experiment 1 suggest that it does not. In this first experiment, orthographic similarity was held constant and phonological similarity was varied, and no effect was observed; in the second experiment, phonological similarity was held constant and orthographic similarity was varied, and here, an effect was observed.

It seems that grapheme-grapheme rules can account for effects that have previously been assumed to involve grapheme-phoneme rules. If this is true, it may be the case that grapheme-phoneme rules are simply not available to readers. One can look at this question by employing a task that optimizes the likelihood that grapheme-phoneme rules will be used. Such a task is one in which subjects must make judgments about the pronunciation of nonwords. In particular, subjects are required to classify a letter string as being or not being pronounced in the same way as a real word. This is a homophone decision task. Thus a "yes" response would be made to BRANE and a "no" response made to BRATE.

If grapheme-phoneme rules are available to a reader, then it would seem that the most logical way of performing this task would be to convert the nonword into a phonological representation via these rules and attempt to match this representation to a lexical representation that is phonologically coded. Baron and Strawson (1976) and Saffran and Marin (1977), who have used this task, assume that this is how it is performed. It is possible, however, that even though this task requires a judgment about pronunciation, subjects employ grapheme-grapheme rules and do not use a mediating phonological representation. By this account, BRANE would be classified as being homophonic with a word because application of the rule A.E $\rightarrow$ AI leads to the accessing of the lexical entry BRAIN. BRATE would be classified as being nonhomophonic with a word because none of the rules for A-E $(\rightarrow \mathrm{AI}, \rightarrow \mathrm{EI}, \rightarrow \mathrm{EIGH}$, $\rightarrow$ AIGH) produces a word.

The method that subjects employ in performing this task can be examined by comparing the 0 -condition nonwords and G-condition nonwords of Experiment 2 in a homophone decision task. If grapheme-grapheme rules were applied, subjects should encounter problems in classifying CHEECE as a nonhomophone compared to BREECE, since only in the former case will a word be accessed, namely, CHEESE. On the other hand, there should be no difference between CHEECE and BREECE if only grapheme-phoneme rules are used, since / $/ \mathrm{C}_{\mathrm{i}} \mathrm{s} /$ is no more similar to / $\mathrm{zi}: z /$ than /bri:s/ is to /bri:z/.

A further consequence of the view that the homophone decision task should be performed via simple application of grapheme-phoneme rules is that there 
should be no difference between pseudohomophones and actual words. To say that RIST is pronounced like a word involves the application of the rules $R \rightarrow / r /$, $\mathrm{I} \rightarrow / \mathrm{I} /, \mathrm{S} \rightarrow / \mathrm{s} /, \mathrm{T} \rightarrow / \mathrm{t} /$ and the accessing of the lexical entry for WRIST, being/rist/. In exactly the same way, to say that RISK is pronounced like a word would involve the application of the rules $\mathrm{R} \rightarrow / \mathrm{r} /, \mathrm{I} \rightarrow / \mathrm{I} /, \mathrm{S} \rightarrow / \mathrm{s} /$, $\mathrm{K} \rightarrow \mathrm{k} /$ and the accessing of the lexical entry for RISK, being /rrsk/. The grapheme-grapheme conversion view, on the other hand, would predict a difference here, since recognition of the pseudohomophone involves the application of at least one rule, whereas the actual word can be accessed without any rule application at all.

Experiment 3 was therefore set up to ascertain whether grapheme-grapheme rules are used instead of grapheme-phoneme rules even in a task that requires decisions to be made about pronunciations.

\section{EXPERIMENT 3}

\section{Method}

Materials. The O-condition and G-condition nonwords that were used in the second experiment were also used in the third experiment.' Thus there were 40 nonhomophonic items, and these are provided in the appendix.

The items for which a positive response was required were either nonwords or words. Twenty pseudohomophones were matched with 20 words on orthographic structure and on frequency of the words they sounded like. For example, RIST was matched with RISK, STAWL with CRAWL, and DUSC with ZINC.

Procedure. The presentation of the items was the same as in the first two experiments. This time, though, subjects were instructed to press the "yes" button if the word was pronounced exactly like an English word and to press the "no" button if it was not. Ample practice was provided so that subjects were clear what the task involved. The experiment questioned al subjects after they had finished to be sure that they pronounced the nonwords in the way that was intended. It was unnecessary to discard any data on this basis. There were 10 subjects in the experiment.

\section{Results and Discussion}

The reaction time and error data for the third experiment are presented in Table 3.

A significant difference between $\mathrm{O}$-condition nonwords and G-condition nonwords was observed for errors $\left[\min F^{\prime}(1,28)=12.01, p<.01\right]$, but not for reaction times $\left(\min \mathrm{F}^{\prime}<1\right)$. In the lexical decision task

Table 3

Mean Reaction Times (in Milliseconds) and Standard Errors Along With Percentage Error Rate (PE) for the Homophone Decision Task of Experiment 3

\begin{tabular}{|c|c|c|c|c|}
\hline Condition & Example & RT & SE & $\mathrm{PE}$ \\
\hline \multicolumn{5}{|c|}{ Not Pronounced Like a Word } \\
\hline $\begin{array}{l}\text { O Nonwords } \\
\text { G Nonwords }\end{array}$ & $\begin{array}{l}\text { CHEECE } \\
\text { BREECE }\end{array}$ & $\begin{array}{l}1470 \\
1443\end{array}$ & $\begin{array}{l}91 \\
92\end{array}$ & $\begin{array}{l}29 \\
10\end{array}$ \\
\hline \multicolumn{5}{|c|}{ Pronounced Like a Word } \\
\hline $\begin{array}{l}\text { Word } \\
\text { Pseudohomophone }\end{array}$ & $\begin{array}{l}\text { RISK } \\
\text { RIST }\end{array}$ & $\begin{array}{r}828 \\
1139\end{array}$ & $\begin{array}{l}44 \\
61\end{array}$ & $\begin{array}{r}4 \\
17\end{array}$ \\
\hline
\end{tabular}

of Experiment 2, the reverse was true. The error difference observed here implies that grapheme-grapheme rules were applied in performing the task. The only reason why subjects should be more inclined to think that CHEECE is pronounced like CHEESE than to think that BREECE is pronounced like BREEZE would seem to be the greater interchangeability of $C$ and $S$ compared to $\mathrm{C}$ and $\mathrm{Z}$. What appears to be happening is that subjects are using a visual rather than phonological strategy in performing this task. Grapheme-grapheme conversions are made, and an attempt is then made to visually access the resultant item in lexical memory. A conversion of $\mathrm{C}$ to $\mathrm{S}$ is worth trying, since it is possible for these letters to be pronounced in the same way, but a conversion of $\mathrm{C}$ to $\mathrm{Z}$ is not worth trying, since they are never pronounced in the same way.

Why is it, then, that subjects do not always make an error on 0-condition nonwords? In the lexical decision task, there can be a visual check after access to determine whether the entry accessed does indeed match with the presented item. In the homophone decision task, a visual check is pointless. Any check that is made to avoid errors must be a phonological one. That is, the pronunciation of the accessed word, as listed in its lexical entry, must be matched with the pronunciation of the presented item. The pronunciation of the presented item could be determined either by grapheme-topronunciation rules (see Coltheart, 1980, Figure 10.1, Pathway C) or by analogy to real words (e.g., Glushko, 1979; Marcel, 1980). Neither of these possibilities necessitates a phonological route to the lexicon. In the former case, a phonological conversion of the graphemes is not used to access the lexicon but, rather, serves as a check with phonological information derived from the lexicon. In the latter case, the lexicon is accessed on a visual basis and the pronunciation is determined from information stored therein.

Why is there no significant reaction time difference between $\mathrm{O}$-condition nonwords and G-condition nonwords? It is possible that, in this difficult task, the influence of gross graphemic similarity was greater than in the lexical decision task. While the two nonhomophone conditions were matched on gross graphemic similarity, the huge variability introduced by it in this task (and possibly by other strategies also) may well have washed out any significant reaction time differences. An error effect was nevertheless observed, since subjects were more likely to make an error not only when the nonword approximately resembled a real word, but also when its resemblance to that real word was rule governed. ${ }^{2}$

Turning to the positive response conditions, it was found that words were responded to far more quickly and with fewer errors than were orthographically similar nonwords [ $\mathrm{min} \mathrm{F}^{\prime}(1,28)=74.01, \mathrm{p}<.001$, for $\mathrm{RT}$, and $\min F^{\prime}(1,19)=5.32, p<.05$, for errors]. This result is not intuitively surprising, yet it is strong evidence against any theory that supposes that phor ogical 
conversion is of primary importance in reading. If lexical access were based solely on grapheme-phoneme rule application, then only the pronunciations of the stimulus items would be important (as well as difficulty of rule application, but this was controlled for). Whether or not the orthography of an item matched with that of a real word should have been irrelevant. Clearly, from the result obtained here, visual access is the primary means of performing the task, such that items that match exactly with a lexical entry can be responded to the most easily.

There is nothing presented in the data so far, however, that denies that access via phonological conversion comes into play in the homophone decision task as soon as direct access fails. The difference between words and pseudohomophones simply says that direct visual access is the first successful approach to the lexicon; it does not say whether or not grapheme-phoneme conversion becomes important whenever direct access fails. The difference between the O-condition and Gcondition nonwords says only that grapheme-grapheme rules are employed in the task at some stage; it does not say whether or not they are brought into play only after direct visual access and phonological access fail.

In order to examine whether grapheme-phoneme conversion is more important in the homophone decision task than is grapheme-grapheme conversion, one needs to look at a situation in which direct access fails to locate a lexical entry but phonological access should not fail. That is, one needs to manipulate the pseudohomophone condition. This was done in the fourth experiment.

\section{EXPERIMENT 4}

If the homophone decision task is primarily carried out via grapheme-phoneme conversion rules (when direct visual access fails), it should then be the case that the orthographic similarity of a pseudohomophone to the word with which it is homophonic should not have any influence on responses. For example, it should not matter whether the word /skri:m/ is presented as SKREAM or SKREME, even though the former is orthographically more similar to SCREAM than is the latter. In both cases, grapheme-phoneme rules would be applied to produce /skri:m/ and, thus, access would be based on the same representation. Grapheme-grapheme rule application, on the other hand, would lead to SKREME being more difficult than SKREAM, since the former involves more conversions $(\mathrm{K} \rightarrow \mathrm{C}, \mathrm{E}-\mathrm{E} \rightarrow \mathrm{EA})$.

It is possible, however, that the grapheme-phoneme rule $\mathrm{E}-\mathrm{E} \rightarrow / \mathrm{i}: /$ takes longer to apply than $\mathrm{EA} \rightarrow / \mathrm{i}: /$, since it is rarer. If this were so, however, then not only would SKREME be harder than SKREAM, but SKEME (homophonic with SCHEME) would be harder than SKEAM. Should the number of grapheme-grapheme conversions be important instead, SKEME should be easier than SKEAM. Similarly, the grapheme-grapheme account would expect PURCE to be easier that PERCE, but VERCE to be easier than VURCE, whereas the graphemephoneme account would not expect this crossover with orthographic structure. Experiment 4 was designed to test the effects of the orthographic similarity of the pseudohomophones to the words with which they are homophonic.

An additional prediction of the grapheme-grapheme account was also tested in Experiment 4. When a nonword is not homophonic with any word, it should be the case that all possible grapheme-grapheme conversions are attempted before a "no" response is made, just in case one of them does produce a correct spelling. If this is so, then subjects should take longer to classify as a nonhomophone any nonword whose pronunciation can be spelled in a number of ways compared to one whose pronunciation can be spelled in only one way. For example, no grapheme-grapheme conversions are possible with the nonhomophone TARL, except for ones that violate orthotactic rules, such as TARRL $(R \rightarrow R R)$ or TAWRL $(R \rightarrow W R)$. Thus response times should be faster to TARL than to RAWL, for which a number of legal conversions are possible, such as $R \rightarrow W R$, $\mathrm{R} \rightarrow \mathrm{RH}, \mathrm{AW} \rightarrow \mathrm{AU}$, and $\mathrm{AW} \rightarrow \mathrm{AL}$ (as in WALK). Again, on the basis of grapheme-phoneme conversion (and also gross graphemic similarity), there should be no difference between a nonword like TARL and a nonword like RAWL.

\section{Method}

Materials. Two different types of pseudohomophones were constructed: one in which only a single grapheme-grapheme conversion was performed on the homophonic word (e.g., SCREAM, SKEME, PURCE, VERCE), and one in which two conversions were performed (e.g., SKREME, SKEAM, PERCE, VURCE). For every item in the one-grapheme-change condition, there was an item of similar orthographic structure in the twographeme-change condition (e.g., SKREAM and SKEAM; SKEME and SKREME; PURCE and VURCE; VERCE and PERCE).

There were two lists of items constructed, each presented to a different group of subjects. Each list contained eight onegrapheme-change pseudohomophones and eight two-graphemechange pseudohomophones in such a way that no one subject saw both spellings of the one homophone. For example, one group received SKREAM and SKEME as one-grapheme-change pseudohomophones and PERCE and VURCE as two-graphemechange pseudohomophones; the other group received PURCE and VERCE and SKREME and SKEAM.

In addition to the pseudohomophones, 10 nonhomophonic nonwords were constructed so that no grapheme-grapheme rules could be applied to them (e.g., TARL, GWELVE). Matched with these on length were 10 nonhomophonic nonwords to which grapheme-grapheme rules could be applied (e.g., RAWL, KWIEVE). ${ }^{3}$ Both groups of subjects received the same 20 nonhomophonic nonwords.

Procedure. The procedure was the same as for Experiment 3 , but this time there were two groups of subjects, with eight subjects in each group.

\section{Results}

Table 4 provides reaction times and error rates for the fourth experiment. The amount of orthographic similarity between a pseudohomophone and the word 
Table 4

Mean Reaction Times (in Milliseconds) and Standard Errors Along With Percentage Error Rate (PE) for the Homophone Decision Task of Experiment 4

\begin{tabular}{|c|c|c|c|c|}
\hline Condition & Example & RT & SE & PE \\
\hline \multicolumn{5}{|c|}{ Pronounced Like a Word } \\
\hline $\begin{array}{l}\text { One-Grapheme Conversion } \\
\text { Two-Grapheme Conversion }\end{array}$ & $\begin{array}{l}\text { SKREAM } \\
\text { SKREME }\end{array}$ & $\begin{array}{l}1007 \\
1194\end{array}$ & $\begin{array}{l}39 \\
54\end{array}$ & $\begin{array}{r}7 \\
30\end{array}$ \\
\hline \multicolumn{5}{|c|}{ Not Pronounced Like a Word } \\
\hline $\begin{array}{l}\text { Rules Applicable } \\
\text { Rules Not Applicable }\end{array}$ & $\begin{array}{l}\text { RAWL } \\
\text { TARL }\end{array}$ & $\begin{array}{l}1512 \\
1362\end{array}$ & $\begin{array}{l}56 \\
73\end{array}$ & $\begin{array}{r}16 \\
8\end{array}$ \\
\hline
\end{tabular}

with which it is homophonic was found to have an effect on homophone decision times. The one-grapheme-change condition was easier than the two-grapheme-change condition as measured both by reaction time $\left[\mathrm{min} \mathrm{F}^{\prime}(1,26)\right.$ $=9.43, \mathrm{p}<.01]$ and by errors $\left[\mathrm{min} \mathrm{F}^{\prime}(1,25)=9.02\right.$, $\mathrm{p}<.01$ ].

It was also found that the nonhomophone manipulation was significant. When grapheme-grapheme rules were possible to apply, subjects took longer than when there were no possible rules $\left[\min F^{\prime}(1,21)=4.83\right.$, $\mathrm{p}<.05]$. The error difference was significant only on the subject analysis $\left[F_{1}(1,15)=10.35, \quad p<.01\right.$; $\left.F_{2}(1,9)=3.64, p>.05\right]$.

\section{Discussion}

Looking at the pseudohomophones first, it can be seen that a decision about the pronunciation of an item is influenced by orthographic factors. If pronunciation were determined primarily by grapheme-phoneme rules (even as a backup to failed direct visual access), then the only factor influencing performance should be the difficulty of applying such rules. This experiment holds constant this factor of rule difficulty and yet finds that the more orthographically similar the nonword is to the word, the more difficult is the response. If grapheme-phoneme rules are used at all, they certainly appear to play very much a secondary role to visual access. Together with the findings of the previous experiment, it can be said that, even in a task that optimizes the likelihood that grapheme-phoneme rules will be used, the application of grapheme-grapheme rules appears to be the preferred method of performing the task.

The finding of a delay in reaction times to nonhomophones for which grapheme-grapheme rules can be applied further supports this view. With items like RAWL, there is a need to try out a number of graphemegrapheme conversions before a "no" response can be made. With items like TARL, subjects can respond more rapidly because the absence of any appropriate grapheme-grapheme rules means that the item cannot be homophonic with a word.

\section{GENERAL DISCUSSION}

Taken together, the four experiments reported raise doubts about the existence of a phonological route to the lexicon via grapheme-phoneme rule conversion. Even if such a route does exist, it certainly appears to play very much of a secondary role in visual word recognition. The two findings that have been previously taken as evidence for the existence of a phonological route to the lexicon, namely, the pseudohomophone effect and the ability to perform the homophone decision tasks, have been shown here to be explainable by a visual route using grapheme-grapheme rule conversion.

When dyslexic subjects fail to produce a pseudohomophone effect and, in addition, are unable to successfully perform the homophone decision task, it may be because they are unable to apply graphemegrapheme rules, and not because they have an impaired phonological route to the lexicon. They do, however, seem to have a further disability in that they are unable to pronounce nonwords. This implies that they have an impairment of the mechanism that gets from the printed word to its pronunciation, be it by grapheme-topronunciation rules (Coltheart, 1980) or by an analogy technique (Glushko, 1979; Marcel, 1980). This impairment means that, when RAYON is generated as being homophonic with RAYNE (on the basis of gross graphemic similarity), the postaccess check for correct pronunciation cannot be carried out and, hence, the error is maintained. Normal readers may also generate RAYON from RAYNE but reject it when the phonological check fails. On the other hand, the word RAIN, generated by grapheme-grapheme conversion, would be accepted after the phonological check is made.

The main problem with the view expressed in this paper is, of course, the counterintuitive nature of the existence of grapheme-grapheme rules. Graphemephoneme rules have been rationalized by assuming that beginning readers make use of their already extant phonologically accessible lexicon by simply converting the written word into a phonological form. The evidence presented here, however, suggests that adult readers no longer do this, at least as the primary means of word recognition. Instead, phonological access might be seen as a backup for visual access when visual access fails (as also suggested by Coltheart). But when does visual access fail in everyday reading?

One encounters nonwords in normal reading only when one reads new words, proper names, misprints, or misspellings. Application of grapheme-phoneme rules will be of use in understanding new words or proper names only if those words have been encountered before verbally and if they have a regular pronunciation. Even then, it is possible for there to have been an orthographic representation set up when the word was first encountered verbally (cf. Tanenhaus, Flanigan, \& Seidenberg, 1980), hence rendering phonological conversion unnecessary. Grapheme-phoneme conversion would be of use in understanding a misprint or a misspelling only if the error were phonologically identical to the intended word. If it were not, only gross graphemic approximation would lead to recognition. However, when grapheme-phoneme conversion could be used, 
grapheme-grapheme conversion could be as equally effectively used. It seems, therefore, that there is as much of a rationale in postulating grapheme-grapheme conversion as there is of postulating grapheme-phoneme conversion in normal adult word recognition.

Grapheme-phoneme rules, however, might be considered important in word recognition for the beginning reader. The child enters the reading situation with a lexicon that is accessible only on a phonological basis. If the printed word can be converted into a phonological form on the basis of rules, then the already extant lexicon can be accessed. However, the rules used need not be grapheme-phoneme rules but, rather, may be the grapheme-pronunciation rules that adults possibly use in determining the pronunciation of nonwords. By this account, the child overtly pronounces the word by rule and then the output of this passes through the normal speech recognition system. That is, the child can read only by speaking the word aloud, and, in fact, that is exactly what beginning readers seem to do. The transition to silent reading might take place either when a direct orthographic access route is acquired or when the grapheme-pronunciation rules become more abstract and become grapheme-phoneme rules. The present results support the former alternative.

It would be at this transition stage that graphemegrapheme rules develop. Knowledge of graphemegrapheme correspondences must originate from pronunciational knowledge. However, once the transition to direct orthographic access is completed, these two types of knowledge become independent, in that the grapheme-grapheme rule system provides knowledge about phonological relationships between words without recourse to phonological recoding.

\section{REFERENCES}

Baron, J., \& Strawson, C. Use of orthographic and wordspecific knowledge in reading words aloud. Journal of Experimental Psychology: Human Perception and Performance, 1976, 2, 386-393.

Carroll, J. B., Davies, P., \& Richman, B. The American Heritage word frequency book. Boston: Houghton-Mifflin, 1971.

Chambers, S. M. Letter and order information in lexical access. Journal of Verbal Learning and Verbal Behavior, 1979, 18, 225-241.

Coltheart, M. Lexical access in simple reading tasks. In G. Underwood (Ed.), Strategies of information processing. London: Academic Press, 1978.

Coltheart, M. Reading, phonological recoding, and deep dyslexia. In M. Coltheart, K. E. Patterson, \& J. C. Marshall (Eds.), Deep dyslexia. London: Routledge \& Kegan Paul, 1980.

Coltheart, M., Davelaar, E., Jonasson, J. T., \& Begner, D. Access to the internal lexicon. In S. Dornic (Ed.), Attention and performance VI. Hillsdale, N.J: Erlbaum, 1977.

Davelan, E., Coltheart, M., Besner, D., \& Jonasson, J. T. Phonological recoding and lexical access. Memory \& Cognition, $1978,6,391-402$.
GLUSHкo, R. J. The organization and activation of orthographic knowledge in reading aloud. Journal of Experimental Psychology: Human Perception and Performance, 1979, 5, 674-691.

Govor, P. B., \& CoskY, M. J. One second of reading again. In N. Castellan, D. B. Pisoni, \& G. R. Potts (Eds.), Cognitive theory (Vol. 2). Hillsdale, N.J: Erlbaum, 1977.

MARCEL, A. J. Surface dyslexia and beginning reading: A revised hypothesis of the pronunciation of print and its impairments. In M. Coltheart, K. E. Patterson, \& J. C. Marshall (Eds.), Deep dyslexia. London: Routledge \& Kegan Paul, 1980.

MCQUADE, D. V. Variable reliance on phonological information in visual word recognition. Language and Speech, 1981, 24, 99-109.

Patterson, K. E., \& Marcel, A. J. Aphasia, dyslexia and the phonological coding of written words. Quarterly Journal of Experimental Psychology, 1977, 29, 307-318.

Rubenstein, H., Lewis, S. S., \& Rubenstein, M. A. Evidence for phonemic recoding in visual word recognition. Journal of Verbal Learning and Verbal Behavior, 1971, 10, 645-657.

Saffran, E. M., \& Marin, O. S. M. Reading without phonology: Evidence from aphasia. Quarterly Journal of Experimental Psy. chology, 1977, 29, 515-526.

TAFT, M. Lexical access via an orthographic code: The Basic Orthographic Syllabic Structure (BOSS). Journal of Verbal Learning and Verbal Behavior, 1979, 18, 21-39. (a)

TAFT, M. Recognition of affixed words and the word frequency effect. Memory \& Cognition, 1979, 7, 263-272. (b)

TAFT, M. Prefix stripping revisited. Journal of Verbal Learning and Verbal Behavior, 1981, 20, 289-297.

TAFT, M., \& Forster, K. I. Lexical storage and retrieval of prefixed words. Journal of Verbal Learning and Verbal Behavior, $1975,14,638-647$.

Tanenhaus, M. K., Flanigan, H. P., \& Seidenberg, M. S. Orthographic and phonological activation in auditory and visual word recognition. Memory \& Cognition, 1980, 8, 513-520.

\section{NOTES}

1. Two G-condition items were in fact changed for Experiment 3. CAUVE was changed to GAUVE and BOOL was changed to HOOL, since it was realized that CAUVE could be pronounced like COVE (as in MAUVE) and BOOL could be pronounced like BULL (as in WOOL).

2. It is interesting to note that, inadvertently, one of the G-condition nonwords turned out to be homophonic with a word, but an inflected one: CREEST being homophonic with CREASED. Since only 2 of the 10 subjects detected this, it is tempting to see this as evidence for morphological decomposition (Taft, 1979b, 1981; Taft \& Forster, 1975). That is, lexical access is performed on the basis of the stem of a word (e.g., CREASE) and not on the inflected word as a whole.

3. Some of the items used in the experiment did not comply with orthotactic rules. For example, GW occurs initially only in proper names (GWEN), and $\mathrm{KW}$ occurs initially only in brand names (KWIK-GRIP). It was considered that this would not be important, however, since orthotactic rules are only relevant when a decision is to be made about the "Englishness" of the orthography of an item. In this experiment, the nonword item itself was not the subject of such a decision. On the other hand, the decision whether or not a letter string created by the application of grapheme-grapheme rules is a word may well be influenced by the Englishness of that letter string, and thus the orthotactic characteristics of the letter strings created by grapheme-grapheme rules are important. 
APPENDIX

Table A

Lexical Decision Times ( $T$ ) and Errors (E) for the Nonword Items Used in Experiment 1

\begin{tabular}{|c|c|c|c|c|c|c|c|c|}
\hline \multicolumn{3}{|c|}{ H Nonwords } & \multicolumn{3}{|c|}{ O Nonwords } & \multicolumn{3}{|c|}{ N Nonwords } \\
\hline & $\mathrm{T}$ & $\mathrm{E}$ & & $\mathrm{T}$ & $\mathrm{E}$ & & $\mathbf{T}$ & $\mathrm{E}$ \\
\hline GLOE & 750 & 1 & BROE & 758 & 0 & SPOE & 710 & 1 \\
\hline SAIVE & 763 & 3 & HAIVE & 803 & 4 & FAIVE & 701 & 0 \\
\hline MUVE & 740 & 0 & DUVE & 755 & 1 & BUVE & 704 & 0 \\
\hline YOOTH & 726 & 4 & MOOTH & 793 & 7 & NOOTH & 729 & 2 \\
\hline TUTCH & 707 & 2 & PUTCH & 831 & 5 & RUTCH & 718 & 0 \\
\hline HOAZE & 744 & 2 & LOAZE & 683 & 0 & MOAZE & 732 & 2 \\
\hline TOOM & 737 & 5 & COOM & 727 & 1 & YOOM & 743 & 2 \\
\hline HOAM & 741 & 1 & SOAM & 718 & 2 & GOAM & 722 & 1 \\
\hline GHOAST & 726 & 0 & FROAST & 731 & 0 & PLOAST & 691 & 0 \\
\hline LEACE & 756 & 2 & TEACE & 716 & 2 & HEACE & 769 & 3 \\
\hline BRETH & 735 & 3 & WRETH & 790 & 1 & FRETH & 674 & 1 \\
\hline LEEF & 761 & 4 & $\mathrm{DEEF}$ & 772 & 0 & SEEF & 757 & 0 \\
\hline PLEED & 816 & 10 & DREED & 787 & 2 & CLEED & 743 & 0 \\
\hline WOSP & 759 & 0 & GOSP & 740 & 1 & DOSP & 703 & 0 \\
\hline WOOND & 772 & 2 & ROOND & 693 & 5 & TOOND & 661 & 1 \\
\hline JERM & 744 & 0 & JIFT & 849 & 0 & JILK & 667 & 0 \\
\hline WIRK & 711 & 0 & FIRK & 682 & 0 & SIRK & 714 & 0 \\
\hline DERTH & 742 & 5 & HERTH & 772 & 0 & LERTH & 688 & 1 \\
\hline SWARE & 833 & 5 & CLARE & 795 & 10 & PLARE & 716 & 1 \\
\hline FLUD & 796 & 2 & BRUD & 672 & 1 & GRUD & 683 & 2 \\
\hline
\end{tabular}

Table B

Lexical Decision Times (LT) and Errors (LE) for Nonword Items in Experiment 2, Along With Homophone Decision Times (HT) and Errors (HE) for Those Items in Experiment 3

\begin{tabular}{|c|c|c|c|c|c|c|c|c|c|c|c|}
\hline \multicolumn{6}{|c|}{ O Nonwords } & \multicolumn{6}{|c|}{ G Nonwords } \\
\hline & & $\mathbf{L T}$ & LE & HT & $\mathrm{HE}$ & & & LT & LE & - HT & $\mathrm{HE}$ \\
\hline STEEK & (steak) & 655 & 0 & 1540 & 4 & FLEEK & (fleck, flake) & 595 & 0 & 1214 & 0 \\
\hline TOWCH & (touch) & 683 & 2 & 1402 & 1 & MOWCH & (much) & 590 & 0 & 1444 & 0 \\
\hline SWARD & (sword) & 649 & 0 & 1430 & 4 & SWOFT & (swift, soft) & 706 & 3 & 1400 & 0 \\
\hline CHEECE & (cheese) & 735 & 0 & 1683 & 4 & BREECE & (breeze) & 734 & 2 & 1616 & 0 \\
\hline SWEER & (swear) & 807 & 1 & 1549 & 2 & BLEER & (bleed, blare) & 619 & 1 & 1431 & 2 \\
\hline BRODE & (broad) & 830 & 0 & 1506 & 2 & FRODE & (froze, fraud) & 594 & 0 & 1293 & 1 \\
\hline HALPH & (half) & 563 & 0 & 1349 & 3 & STALPH & (stalk, staff) & 611 & 0 & 1348 & 0 \\
\hline HIERCE & (hearse) & 690 & 0 & 1486 & 1 & VIERCE & (verse) & 632 & 0 & 1339 & 1 \\
\hline YOWTH & (youth) & 605 & 2 & 1533 & 4 & TOWTH & (tooth) & 631 & 0 & 1546 & 3 \\
\hline KELL & (cell) & 725 & 1 & 1371 & 1 & KEND & (send) & 607 & 0 & 1358 & 0 \\
\hline COAPY & (copy) & 616 & 0 & 1481 & 1 & POAPY & (poppy) & 601 & 0 & 1673 & 2 \\
\hline WICE & (wise) & 715 & 0 & 1253 & 1 & SICE & (size) & 616 & 0 & 1470 & 1 \\
\hline CHALC & (chalk) & 648 & 0 & 1303 & 6 & HALC & (halt, hawk) & 682 & 0 & 1415 & 0 \\
\hline SOOL & (soul) & 734 & 2 & 1320 & 1 & BOOL & (bowl) & 610 & 0 & $1326^{*}$ & 0 \\
\hline BREEST & (breast) & 725 & 0 & 1498 & 2 & CREEST & (crest) & 662 & 0 & 1601 & 2 \\
\hline HAIVE & (have) & 632 & 1 & 1695 & 2 & CAUVE & (cave) & 680 & 0 & $1351^{*}$ & 1 \\
\hline MUSKLE & (muscle) & 630 & 0 & 1445 & 6 & RUSKLE & (rustle) & 627 & 1 & 1378 & 1 \\
\hline WUDE & (wood) & 639 & 0 & 1584 & 5 & SHUDE & (shade, should) & 637 & 0 & 1692 & 3 \\
\hline GLOAVE & (glove) & 682 & 1 & 1380 & 3 & PROIVE & (prove) & 652 & 0 & 1380 & 3 \\
\hline SOOGAR & (sugar) & 668 & 0 & 1652 & 4 & SOOVEL & (shovel) & 624 & 0 & 1723 & 0 \\
\hline
\end{tabular}

Note-Words in parentheses are words that are graphemically and/or phonemically similar to the nonword item. *See Footnote 1 .

Table C

Homophone Decision Times (T) and Errors (E) for the Homophonic Items in Experiment 4

\begin{tabular}{lcclcc}
\hline & One-Grapheme Change & & \multicolumn{3}{c}{ Two-Grapheme Change } \\
\cline { 2 - 3 } & $\mathrm{T}$ & $\mathrm{E}$ & & $\mathrm{T}$ & $\mathrm{E}$ \\
\hline SKEME & 937 & 0 & SKEAM & 1008 & 1 \\
SKREAM & 862 & 0 & SKREME & 1278 & 0 \\
PURCE & 958 & 0 & PERCE & 1344
\end{tabular}


Table C Continued

\begin{tabular}{|c|c|c|c|c|c|}
\hline \multicolumn{3}{|c|}{ One-Grapheme Change } & \multicolumn{3}{|c|}{ Two-Grapheme Change } \\
\hline & $\mathrm{T}$ & $\mathrm{E}$ & & $\mathrm{T}$ & $\mathrm{E}$ \\
\hline VERCE & 947 & 2 & VURCE & 1628 & 3 \\
\hline SKAIT & 843 & 0 & SCAIT & 1246 & 1 \\
\hline SCAIR & 890 & 0 & SKAIR & 1003 & 0 \\
\hline ROAP & 1026 & 0 & WROAP & 1192 & 2 \\
\hline WREQUE & 1102 & 0 & REQUE & 1150 & 4 \\
\hline ROOLE & 1080 & 0 & ROOL & 969 & 2 \\
\hline SOOP & 1084 & 2 & SOOPE & 1185 & 1 \\
\hline PHEIGN & 1188 & 1 & PHANE & 1198 & 7 \\
\hline KRANE & 858 & 0 & KREIGN & 1021 & 5 \\
\hline GNOAM & 1156 & 3 & KNOAM & 1144 & 2 \\
\hline KNEAL & 820 & 0 & GNEAL & 998 & 3 \\
\hline SKWIRM & 1187 & 0 & SKWERM & 1373 & 0 \\
\hline PHERN & 1259 & 1 & PHIRN & 1394 & 5 \\
\hline
\end{tabular}

Table D

Homophone Decision Times (T) and Errors (E) for the Nonhomophonic Items in Experiment 4

\begin{tabular}{|c|c|c|c|c|c|}
\hline \multicolumn{3}{|c|}{ Rules Applicable } & \multicolumn{3}{|c|}{ Rules Not Applicable } \\
\hline & $T$ & $\mathrm{E}$ & & $\mathrm{T}$ & $\mathbf{E}$ \\
\hline RAWL & 1526 & 2 & TARL & 1159 & 1 \\
\hline SKACE & 1354 & 1 & SPANT & 1265 & 0 \\
\hline PHLESK & 1385 & 6 & THRISP & 1216 & 2 \\
\hline CLEED & 1406 & 0 & BLOIN & 1437 & 0 \\
\hline WRAD & 1472 & 1 & PRUB & 1228 & 3 \\
\hline JIRCE & 1434 & 0 & LINGE & 1518 & 0 \\
\hline KWIEVE & 1582 & 4 & GWELVE & 1422 & 1 \\
\hline WOONE & 1465 & 8 & VOOTH & 1488 & 2 \\
\hline KRAIST & 1644 & 2 & GLANCH & 1233 & 2 \\
\hline WHOSC & 1671 & 2 & DWUSP & 1436 & 1 \\
\hline
\end{tabular}

(Received for publication November 24, 1981;

revision accepted May 11, 1982.) 